\title{
UN FACISTOL MANIERISTA EN LANCIEGO (ÁLAVA). EL REPERTORIO ORNAMENTAL BELIFONTIANO EN LA DIÓCESIS DE CALAHORRA*
}

\author{
Pedro Luis Echeverria Goñi ${ }^{1}$ \\ José Javier Vélez Chaurri² \\ Universidad del País Vasco \\ 'pedroluis.echeverria@ehu.eus \\ 2josejavier.velez@ehu.eus
}

RESUMEN: Damos a conocer aquí el extraordinario facistol renacentista de la parroquia de Lanciego realizado a fines del segundo tercio del siglo XVI. Es una obra de carácter internacional, salida del taller del maestro francés Esteban Bertín de París. Tras su análisis pormenorizado, llegamos a la conclusión de que se trata de una obra manierista que muestra un variado repertorio de motivos decorativos fantásticos, inspirados en grabados de la Escuela de Fontainebleau. Entre ellos sobresalen los seis hermes masculinos y femeninos que constituyen el conjunto más importante de este soporte antropomorfo en el País Vasco.

Palabras clave: Facistol, sillería de coro, Manierismo, Fontainebleau, belifontiano, hermes, término, cariátide, máscara, cartela, correiforme, Lanciego, Esteban Bertín de París, Arnao de Bruselas.

\section{A MANNERIST LECTERN IN LANCIEGO (ÁLAVA). THE BELLEFONTAINE ORNAMENTAL REPERTOIRE IN THE DIOCESE OF CALAHORRA}

ABSTRACT: We bring to light the extraordinary renaissance lectern, from the Parish Church of Lanciego made at the end of the second third of the sixteenth century. It is a work of an international character, from the workshop of the French master Esteban Bertin of Paris. After its detailed analysis, we conclude that it is a mannerist work that shows a varied repertoire of fantastic decorative motifs inspired by the School of Fontainebleau prints. Among them stands out

* Este trabajo se ha realizado en el marco del Grupo de Investigación Consolidado del Gobierno Vasco "Sociedad, Poder y Cultura (siglos XIV XVIII)", IT896 162016. 
the six male and female Hermes which is the most important anthropomorphic support group in the Basque Country.

Keywords: Lectern, choir stalls, Mannerism, Fontainebleau, belifontiano, hermes, term, cariatyd, mask, cartouche, strapwork, Lanciego, Esteban Bertin de Paris, Arnao de Bruselas.

La villa de Lanciego atesora importantes obras de talla policromada de los siglos XIV al XVIII en su parroquia y la ermita de Nuestra Señora del Campo. Preside el retablo de esta última una imagen gótica de la Virgen con el Niño, que responde a la tipología de las Andra Mari del siglo XIV. Ha llegado a nuestros días en la iglesia parroquial, reaprovechado en el retablo barroco de Santa Ana, un escenográfico relieve expresivista con la Sagrada Familia acompañada de Santa Ana y San Joaquín, salido del taller de Andrés de Araoz. Preside el altar mayor uno de los más tempranos y excepcionales retablos romanistas del País Vasco, ejecutado por Juan Fernández de Vallejo entre 1567 y 1569. El Barroco tiene en este templo buenos exponentes en la talla del Crucificado que preside su retablo, realizado en 1718, y en la sillería rococó de $1769^{1}$. Pero una de las piezas más excepcionales que atesora este templo es el fuste del facistol renacentista de hacia 1563 , que sacamos a la luz en este estudio y que

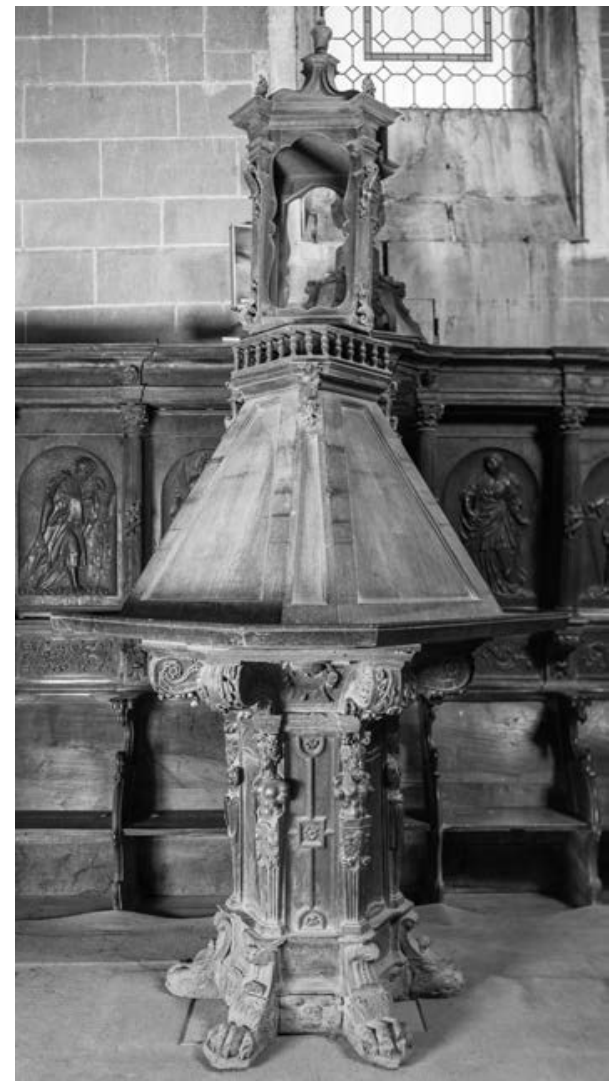

Figura 1. Facistol. Parroquia de San Acisclo y Santa Victoria. Lanciego (Álava).

1. ENCISO VIANA, E. y CANTERA ORIVE, J., Catálogo Monumental. Diócesis de Vitoria, Tomo I, Rioja Alavesa, Vitoria, Caja de Ahorros Municipal, 1967, pp. 102 105. Otro testimonio del esplendor de Lanciego en los años sesenta del siglo XVI es el terno, formado por capa plu vial y dos dalmáticas, de color rojo con ricos bordados en oro. 
posee uno de los repertorios más in-teresantes del manierismo fantástico en el País Vasco (fig. 1). Es el único resto que ha Ilegado a nuestros días de la primitiva sillería de coro del siglo XVI, que fue sustituida en 1769 por la actual, momento en que se añadió al facistol un nuevo atril y tabernáculo. Curiosamente por las mismas fechas se estaban haciendo en Lanciego un facistol manierista y uno de los primeros retablos miguelangelescos, al igual que estaba ocurriendo en la parroquia de Estavillo con los retablos de la Concepción y el mayor ${ }^{2}$.

La única referencia bibliográfica sobre este mueble lo clasifica como obra coetánea a la sillería dieciochesca ${ }^{3}$, cuando tan solo corresponden a ese momento el atril y el tabernáculo. Aunque jamás ha sido reproducido, su valoración in situ nos ha permitido comprobar que su pie, pilar y peana corresponden al facistol original del siglo XVI. Derivados de grabados ornamentales franceses de la escuela de Fontainebleau se despliegan por toda su superficie motivos como cartelas correiformes, hermes o términos, máscaras, mascarones y telas colgantes. Los seis términos masculinos y femeninos de orden jónico representan el conjunto más importante de este soporte antropomorfo en estas tierras.

La mayor parte de los templos de La Rioja alavesa se ampliaron o construyeron de nueva planta en el segundo tercio del siglo XVI, marcando la finalización de las obras la erección de los coros. Superado el ecuador de esta centuria se construyeron los de Oyón, las dos parroquias de Laguardia, Lanciego, Elciego y Yécora, interviniendo en su construcción especialistas de las familias de los Asteasu, Emasabel y Olate. Tras su conclusión las ricas primicias procedieron a dotarlos de su mueble más específico, las sillerías de coro manieristas que corrieron a cargo de ensambladores y entalladores nórdicos, franceses como Juan de Lorena, Esteban de París, Martín Gumet o Enrique Dreux y flamencos como Nicolás de Holanda. La renovación barroca y neoclásica de los ajuares de estos templos en el siglo XVIII, al dictado de las modas, supuso la desaparición de la casi totalidad de los conjuntos renacentistas conservándose únicamente algunas sillas en San Juan de Laguardia y el facistol de Lanciego.

Aunque carecemos de datos documentales directos sobre el facistol de Lanciego, pensamos que se trata de una pieza sobresaliente de la fase final del manierismo expresivista ejecutada en torno a 1563. En cualquier caso no podemos ignorar que se documenta en esta localidad la presencia en 1567 del

2. ECHEVERRÍA GOÑI, P. L., "Nuevas luces sobre la escultura renacentista en Álava. Fran cisco de Ayala en Estavillo", Estudios de arte. Homenaje al profesor Martín González, Vallado lid, Universidad de Valladolid, 1995, pp. 321 326. Resulta paradójico que el primer retablo romanista de todo el País Vasco (1564) es anterior al retablo de la Concepción, obra expresivista contratada en 1565.

3. ENCISO VIANA, E. y CANTERA ORIVE, J., ob. cit., p. 104, "Las puertas del coro y el facis tol hacen juego con la sillería". 
ensamblador francés Enrique Dreux ${ }^{4}$, así como la existencia del relieve de la Sagrada Familia que denota el estilo de Andrés de Araoz.

Creemos que este facistol se puede poner en la órbita del francés Esteban Bertín o Bartin de París ${ }^{5}$, entallador vecino de Laguardia y activo en ella desde 1551 hasta 1563, a quién a veces se denomina también ensamblador o fustero. Pudo intervenir en este mueble litúrgico el gran imaginero flamenco Arnao de Bruselas, como lo delata la gran calidad de la talla de los hermes. La época fecunda de Bertín, documentada en la Rioja alavesa, abarca la década de los cincuenta y comienzos de la década de los sesenta del siglo XVI, fechándose sus primeras intervenciones en la parroquia de San Juan de Laguardia en 1551, en el guardapolvos del retablo mayor, y 1552, cuando se le paga el "atril que hizo para el choro de Nuestra Señora" ${ }^{\prime \prime}$. Destacan entre su producción las sillerías de coro de las iglesias de San Juan (1557-1558) y de Santa María de Laguardia (1557) y la de Elciego (1559-1561). En la primera, la única renacentista que se conserva parcialmente en todo el territorio, contó con la colaboración de Nicolás van Haarlem ${ }^{7}$ y en la última con la de Martín de Otalora ${ }^{8}$.

Probablemente fue en 1557 cuando "Esteban Bartin, entallador"9 inició la sillería de la parroquia de San Juan de Laguardia "conforme a la traça que yo tengo dada para ella", firmada por él y por los arcedianos de Calahorra y Santo Domingo de la Calzada. El 28 de diciembre de 1558 el entallador francés cedió a Nicolás van Haarlem, ensamblador flamenco, conocido en estos lares como Nicolás de Holanda, la realización de las seis sillas del lado del baptisterio, comprometiéndose a facilitarle "toda la fusta que fuere menester serrada y las

4. Ibid., p. 106, nota 5 .

5. Resulta tentador relacionar a nuestro Esteban Bertín con Dominique Bertín, arquitecto y escultor francés, natural de París y activo en el segundo tercio del siglo XVI, aunque no hemos encontrado ninguna confirmación documental. Sabemos que en 1556 ilustró un extracto de los diez libros de arquitectura de Vitrubio escrito por Jean Gardet. Establecido en Tolouse entre 1551 y 1565, se encargó de la conclusión de la sillería de coro de la catedral de Santa María de Auch. TOLLON, B., "L’Epitome de Vitruve par Jean Gardet et Dominique Bertin, à Tolouse en 1559 (1560)", en Deswarte Rosa, S. (ed.), Sebastiano Serlio à Lyon, Architecture et imprimerie, Lyon, Mémoire Active, 2004, pp. 432 435. MONTANÉ, R., La Cathédrale d'Auch, ses stalles et ses vitraux, La Pierre Qui Vire (Yonne), Les Presses monastiques, 1975.

6. Archivo Histórico Diocesano de Vitoria. Sig. 1382 1. Laguardia. Parroquia de San Juan. Libro de Fábrica, 1532 1556, fol. 131. Se refiere a la antigua capilla de Nuestra Señora del Pilar de Laguardia. Ese año se encargó asimismo de la reja de esta capilla.

7. ENCISO VIANA, E. y CANTERA ORIVE, J., ob. cit., p. 77. Archivo Histórico Provincial de Álava. Sig. Porres, 1558.

8. Ibid., p. 52.

9. Archivo Histórico Diocesano de Vitoria. Sig. 1382 1. Laguardia. Parroquia de San Juan. Libro de Fábrica, 1532 1556, fol. 138v. Terminada la fábrica del coro, en 1556 se registran pago por "poner edictos sobre el coro" que pueden referirse a la convocatoria a remate de la empresa de la sillería coral. 
colunas que para ellas fuere menester, torneadas" 10 . Poco antes recibía pagos de la primicia de Santa María de Laguardia por "los asientos que hizo en el coro de la dicha iglesia"11. Por la sillería de Elciego, de la que no ha quedado ningún resto, cobró la respetable suma de 127 ducados $^{12}$. En 1560 "maestre Esteban" cobraba cerca de 83 ducados "para en pago de la obra que haze en la dicha yglesia", de Lagrán que debe tratarse de las "ymagenes y retablos", mayor y colaterales, para los que acababa de dar licencia el provisor del obispado de Calahorra $^{13}$. El autor principal de estos retablos fue Martín de Otálora que recibía pagos por ellos entre 1563 y $1564^{14}$.

En 1563 Esteban Bertín se presentó, junto a Domingo de Segura, entallador e imaginero vecino de Tudela, al remate del retablo mayor de la parroquia de San Juan Bautista de Estella, junto a otros equipos comandados por maestros franceses como el ensamblador Martín Gumet y los entalladores Pedro de Troas o Pierres Picart, quién finalmente fue el adjudicatario de la obra ${ }^{15}$. No conocemos ningún otro facistol del siglo XVI en esta comarca por lo que debemos poner al de Lanciego en relación con el de Los Arcos, realizado junto a la sillería de coro entre 1561 y 1577, por el maestro francés Martín Gumet ${ }^{16}$ y el imaginero Juan Ruiz de Heredia.

En algunas de las tallas de los hermes del pilar del facistol vemos semblantes y barbas que se repiten en obras del taller de Arnao de Bruselas, considerado el mejor imaginero manierista en el valle medio del Ebro a fines del segundo tercio del siglo $X V^{17}$. Así por ejemplo el autor del hermes de barba ondulada es el mis-

10. Archivo Histórico Provincial de Álava. Sig. 7605, Prot. Not. Juan de Porres, 1558, fols. 1 2. Por su labor quedaba obligado a pagarle 30 ducados de oro, equivalentes a 11.250 mara vedís, incluyendo la manutención.

11. UGALDE GOROSTIZA, A. I., Una mirada al cielo. Iconografía de las claves de bóveda de la Diócesis de Vitoria, Vitoria, Diputación Foral de Álava, 2007, p. 404. Archivo Histórico Dio cesano de Vitoria, Sig. 1449 1, Laguardia, Santa María, Libro de Fábrica, 1549 1624, fol. 47r.

12. ENCISO VIANA, E. y CANTERA ORIVE, J., ob. cit., p. 52. Archivo Histórico Diocesano de Vitoria. Sig. 3845 1. Elciego. Libro de Fábrica, 1552 1579, fols. 57v, 60 y 62v.

13. Archivo Histórico Diocesano de Vitoria. Sig. 8868 2. Lagrán. Libro de Fábrica, 1560 1678, fol. 31.

14. PORTILLA VITORIA, M. J. y EGUÍA LÓPEZ DE SABANDO, J., Catálogo Monumental. Diócesis de Vitoria, Tomo II. Arciprestazgos de Treviño-Albaina y Campezo, Vitoria, Caja de Aho rros Municipal, 1968, p. 283.

15. BIURRUN SOTIL, T., La escultura religiosa y Bellas Artes en Navarra durante la época del Renacimiento, Pamplona, Bescansa, 1935, p. 147. URANGA GALDIANO, J. E., Retablos navarros del Renacimiento, Pamplona, 1947, pp. 21 y 48.

16. BIURRUN SOTIL, T., ob. cit., p. 139.

17. RUIZ NAVARRO PÉREZ, J., Arnao de Bruselas: imaginero renacentista y su obra en el valle medio del Ebro, Logroño, Instituto de Estudios Riojanos, 1981. ECHEVERRÍA GOÑI, P. L., "El retablo de San Esteban. Estilo e iconografía", en Renacimiento y Humanismo en Navarra: El retablo de Genevilla, Panorama no 19, Pamplona, Gobierno de Navarra, 1991, pp. 7 80. FER 
mo, por la identidad plena de sus rasgos, que el soldado en disposición frontal del relieve de San Martín partiendo la capa de la sillería coral de la concatedral de Santa María de la Redonda. La disposición simétrica de sus barbas y el rostro de ceño fruncido y con arrugas los vemos en dos evangelistas del Museo Nacional de Escultura de Valladolid, catalogados como obra del artista flamenco.

Fue tal la fama alcanzada por el facistol de Lanciego que, casi veinte años después de su realización, se proponía como modelo para la ejecución del de la cercana parroquia de Oyón. En el contrato de este facistol, fechado el 25 de marzo de 1582, el ensamblador Pedro de Asiáin, se comprometía a hacerlo "de la misma suerte e manera questá e igual fazistol de la iglesia del lugar de Lanzie$\mathrm{go}^{1{ }^{11}}$. Entre las clausulas se indica que debía ser "de la altura que fuere menester, con que a de ser del pie ariba todo de madera de nogal y el pie de roble". Meses después Asiáin cedió la mitad de la obra al también ensamblador Esteban de Elizalde, ambos procedentes de Viana ${ }^{19}$. Esta pieza, que no ha llegado a nuestros días, fue tasada en 1584 por los ensambladores Martín de Otálora y Tomás de Segura, vecinos de Laguardia y Viana respectivamente, en cien ducados ${ }^{20}$. Sin embargo, en la vecina Labraza se ha conservado completo un facistol manierista de finales del siglo XVI que presenta, garras de león en los pies, estípites en sus seis ángulos, hornacinas simuladas y casetones. De este mismo estilo, aunque más depurado es el facistol de Elvillar realizado a partir de 1611.

El rico repertorio que adorna este facistol procede del manierismo fantástico de la escuela de Fontainebleau. Su punto de partida está en las decoraciones de los marcos de estuco de este palacio real francés, diseñadas en la década de los treinta por Giovanni Battista di Jacopo, conocido como Rosso Florentino, y Francesco Primaticcio. Su éxito, superado el ecuador del siglo $\mathrm{XVI}$, se debió a la difusión de las estampas ornamentales que, fechadas en los años cuarenta, realizaron grabadores franceses como R. Boyvin, A. Fantuzzi o J. Mignon y flamencos ${ }^{21}$. Una fecha de referencia en la introducción de estos motivos en España es el frontispicio del Tercero y Cuarto Libro de Arquitectura

NÁNDEZ PARDO, F. (dir.), La escultura en la ruta jacobea: Arnao de Bruselas, Logroño, Diócesis de Calahorra y La Calzada Logroño, 2005. RAMÍREZ MARTíNEZ, J. M., La evolución del retablo en La Rioja. Retablos mayores, Logroño, Diócesis de Calahorra y La Calzada Logroño, 2010, pp. 62 81. RUIZ NAVARRO PÉREZ, J., "La escultura del Renacimiento y Manierismo en La Rioja", en Arrue, B. (coord.) y Moya, J. G. (dir.), Historia del arte en La Rioja, vol. III: El siglo XVI, Logro ño, Fundación Caja Rioja, 2005, pp. 233241.

18. Archivo General de Navarra. Prot. Not. 59/1. Viana. Pedro de Alegría, 1582, fols. 2627.

19. Ibid, fols. $9393 \mathrm{v}$.

20. Ibid, 59/3, 1584, fols. 279280.

21. ZERNER, H., École de Fontainebleau: gravures, París, Arts et Mètiers graphiques, 1969. BÉGUIN, S., et al., La Galerie de François ler au château de Fontainebleau, París, Flammarion, 1972. LEVÊQUE, J. J., L'École de Fontainebleau, Neuchâtel, Ides et Calendes, 1984. 
de Sebastian Serlio en su traducción castellana de 1552, encuadrado por sendos hermes masculino y femeni$\mathrm{no}^{22}$, que ya aparecían en la primera edición del Libro IV publicado en Venecia de 1537. Podemos considerar como la carta de presentación de esta decoración en la diócesis de Calahorra-La Calzada, el frontispicio de las Constituciones Sinodales de este obispado, salidas del cónclave celebrado en Logroño en 1553 bajo la presidencia de Juan Bernal Díaz de Luco (fig. 2). Se da la circunstancia que fueron editadas en 1555 en la ciudad francesa de Lyon ${ }^{23}$, uno de los centros impresores más importantes del Renacimiento en Europa. El escudo del obispo está enmarcado por una cartela correiforme con hermes, máscaras, telas colgantes y guirnaldas. En el foco calceatense encontramos alguna obra que, de forma pionera, introduce estos motivos, como el retablo de la capilla de San

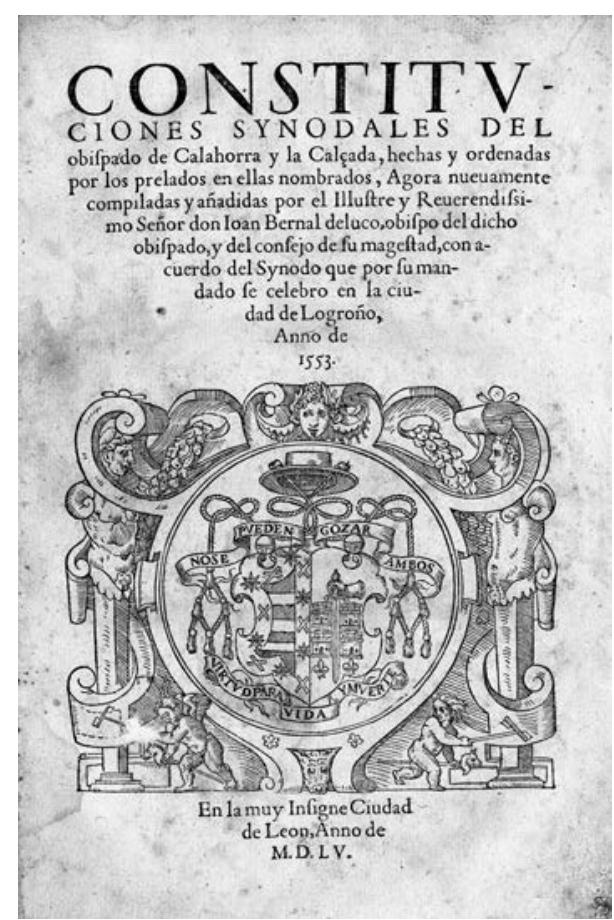

Figura 2. Frontispicio de las Constituciones Sinodales del Obispado de Calahorra y La Calzada. León (Lyon), 1555. Andrés de la catedral de Santo Domingo de la Calzada, cuya traza diseñó el pintor Andrés de Melgar en $1552^{24}$. La plasmación más temprana que conocemos de este repertorio en la Rioja alavesa son los relieves del frente del lado de la epístola del coro de la parroquia de San Juan de Laguardia, ejecutado por el cantero Domingo de Asteasu para

22. SERLIO, S., Tercero y quarto libro de architectura, Toledo, 1552, fol. I. Edición facsímil, Barcelona, Ed. Alta Fulla, 1990.

23. ODRIOZOLA, A., "Libros diocesanos del País Vasco impresos antes del Concilio de Trento", Scripta Victoriense, 29 (1982), p. 235.

24. RAMÍREZ MARTíNEZ, J. M., La evolución del retablo en La Rioja. Retablos mayores, Logroño, Obispado de Calahorra, La Calzada y Logroño, 2009, p. 54. BARRÓN BARRÓN, A., "Espacios funerarios renacentistas en la catedral calceatenese" en Azofra, E. (ed.), La catedral calceatense desde el Renacimiento hasta el presente, Salamanca, Gobierno de la Rioja, 2009, p. 189. Este mismo año de 1552 es el de la muerte del cantero y escultor Juan de Goyaz, que inició el nichal de Santa María de Viana, y en cuyo círculo trabajaron algunos de los mejores imagineros y entalladores del primer Manierismo como Andrés de Araoz, Arnao de Bruselas, Martín de Zaldegui, Nicolás de Venero o Gaspar de Vitoria. 
ese mismo año de $1552^{25}$. El conjunto ornamental más rico con estos motivos fantásticos es, sin duda, el retablo mayor de la parroquia de Elvillar, obra realizada por los Beaugrant, Andrés de Araoz y Arnao de Bruselas en esta misma década de los cincuenta.

La época dorada de este conjunto de motivos belifontianos se inicia realmente en torno a 1558, fecha del fallecimiento del emperador Carlos V, que también aparece grabada en la sillería de coro de la parroquia de San Juan de Laguardia. Este repertorio tuvo gran fortuna en el arte manierista de La Rioja, Navarra y Álava en los años sesenta, perdurando hasta mediados de la década siguiente. Son varias las obras alavesas que muestran en los tercios de talla de las columnas, frisos y ménsulas estos motivos de origen francés como el retablo mayor de la parroquia de San Antolín de Urbina (1560) o el de los Reyes de la de San Pedro de Vitoria (1564), las grisallas de la iglesias de Urbina (1561) y Heredia (1564), o algunas obras pétreas como el retablo de la capilla de San Francisco en la iglesia de Santa María de Salvatierra o la portada de la sacristía de Alegría, las dos últimas fechadas en 1574. Alguno de los retablos salidos de la colaboración entre el taller de Andrés de Araoz y Arnao de Bruselas como el de Genevilla (Navarra), realizado en su mayor parte entre 1558 y 1563, incorporan asimismo estos motivos fantásticos.

El facistol de Lanciego consta de cinco piezas superpuestas de las que las tres primeras, que sirven de asiento al atril, corresponden al primitivo del siglo XVI. El atril y el tabernáculo rococós son obras añadidas en el siglo XVIII y coetáneas a la sillería. Esta pieza giratoria presenta la habitual forma de pirámide truncada con esquinas biseladas mostrando sus frentes cajeados y lisos, donde se colocaban los libros de coro como cantorales y antifonarios. Se remata en balaustrada sustentada por ménsulas rococó de doble voluta que se repiten como aplicaciones en el templete superior. Éste adopta la forma de tabernáculo de planta cuadrada con sus frentes abiertos de marco lobulado y se corona por cúpula rematada en jarrón. Cobijaba originalmente una imagen de la Asunción, que no ha llegado a nuestros días.

El soporte del facistol, compuesto por pie, pilar y peana, constituye la pieza más antigua de la parroquia y es, por su programa plástico profano, una interesante obra del manierismo fantástico de hacia 1563, con característicos motivos de la escuela de Fontainebleau (fig. 3). Algunos de ellos como los hermes, las garras, las ménsulas de doble voluta, las cartelas correiformes y los encadenados geométricos los encontramos también en el tratado de Serlio. Está realizado en madera de nogal, adopta una planta hexagonal y presenta un cierto estrechamiento en su base a modo de estípite. El pie apea en seis airosas ménsulas foliá-

25. AHDV. Sig. 1382 1. Laguardia. Parroquia de San Juan. Libro de Fábrica, 1532 1556, fols. 120, 123v, 124, 124v, 129v, 131 y 134 . 
ceas que terminan en garras de león y, entre ellas, hallamos cartelas correiformes con máscaras; la parte superior la ocupan seis paneles lisos. Vemos estas mismas garras en los pies que sirven de basa a los términos de orden jónico de una chimenea dibujada por Serlio ${ }^{26}$. Idénticos apoyos presentan varios diseños de J. Androuet du Cerceau, como una mesa cuyas patas apoyan en tres garras a modo de trípode ${ }^{27}$ y una cartela ornamental de la serie de los "Petits Cartouches" (1545-1547), aunque en este caso las garras son foliáceas ${ }^{28}$. Encontramos garras leoninas similares en patas de sillas que aparecen en relieves de Arnao de Bruselas como vemos por ejemplo en el de San Mateo de la sillería de La Redonda. El facistol de la iglesia de Los Arcos, coetáneo al de

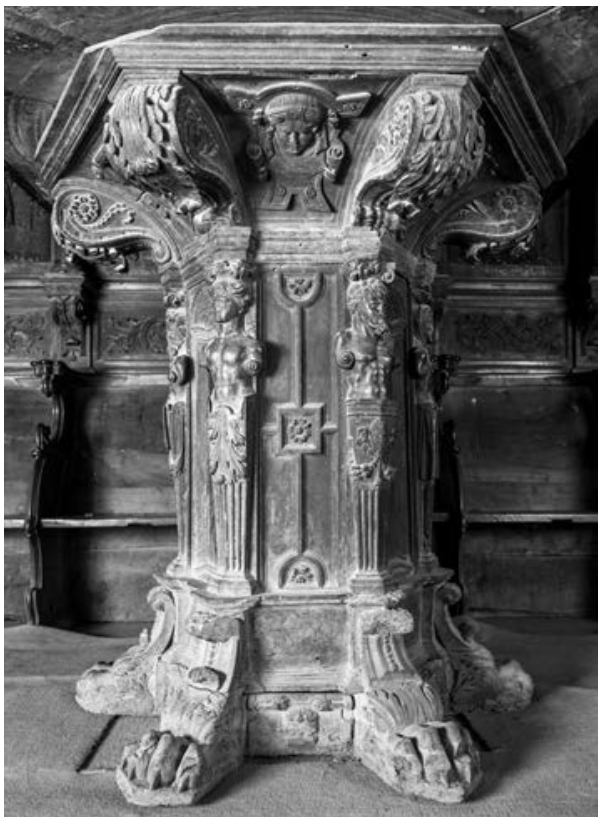

Figura 3. Pie y pilar del facistol. Lanciego, presenta un pie apoyado en leones, en tanto que en el posterior de Labraza lo hacen asimismo sobre garras leoninas.

El pilar hexagonal muestra en sus ángulos seis hermes masculinos y femeninos alternantes, que constituyen el único conjunto monumental de este motivo manierista en territorio alavés (fig. 4). Por su carácter de soporte, los hermes se localizan en pilares y diseños de mobiliario como candelabros, aguamaniles y diversos astiles como vemos por ejemplo en los grabados realizados por R. Boyvin, a partir de $1540^{29}$. Enmarcan otros tantos paneles en los que se suceden motivos geométricos con florones y esbeltas hornacinas; éstas se disponen en esviaje sobre pilastras acanaladas y muestran la rosca del arco recorrida por encadenados geométricos. Guardan gran semejanza con las hornacinas de los tableros de la sillería de coro de San Juan de Laguardia, realizada en 1558, y con la citada de Los Arcos.

Los hermes o términos son soportes antropomorfos formados por un estípite rematado por un tronco y cabeza humanos que hace referencia a Termi-

26. SERLIO, S., Tercero y quarto libro de architectura, fol. XLVIII.

27. Oeuvre de Jacques Androuet dit du Cerceau, Meubles, París, 1886, lám. 15.

28. RijksMuseum. Collection, Prints, Catalogue reference. Orn. Cat. I 542.26.

29. Victoria and Albert Museum. Prints and drawings, E 10221908. 
nus, antigua divinidad romana de la muerte que tenía una capilla en el Capitolio romano. En la Antigüedad estuvieron colocados como señal de protección en puertas, jardines $y$, sobre todo, en caminos y campos como piedras miliarias o mojones. Cuando la figura es femenina recibe también el nombre de hermacariátide. Encontramos su antecedente en los soportes antropomorfos que Vitruvio denomina en los diez libros de arquitectura, "cariátides", "persas", "telamones" y "atlantes" ${ }^{\prime \prime 30}$. Este ornamento arquitectónico manierista fue divulgado a través de grabados franceses y flamencos y se mantuvo vigente hasta pleno siglo $\mathrm{XVIII}{ }^{31}$. La primera definición de hermes que encontramos en la tratadística hispana

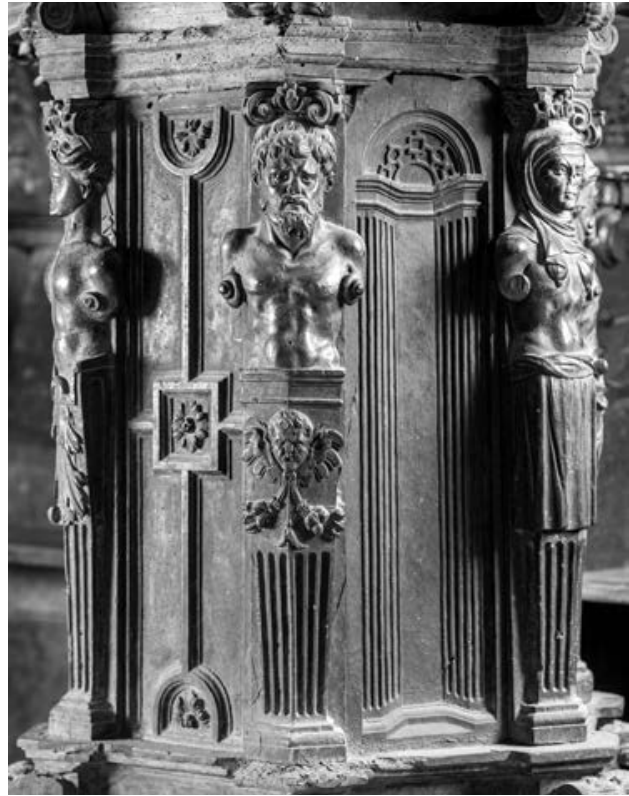

Figura 4. Pilar del facistol con hermes, encadenado geométrico y arco en perspectiva.

del Renacimiento aparece en De Varia Commensuración de Juan de Arfe (1585), cuando nos dice que "los términos, qes una manera de columnas tomadas de las Caryátides y Pérsicas, que primero usaron los Griegos" ${ }^{\prime \prime 2}$. En el emblema CLVII, "Terminus", de Andrea Alciato leemos que "es el término que representa un obstáculo para los hombres" ${ }^{\prime 33}$. En los programas neoplatónicos los hermes manieristas plasman las energías oscuras de la materia y la degradación del ser humano convertido en soporte $^{34}$, y precisamente por ello se tallan en el pilar del facistol.

30. VITRUVIO, M., Los Diez Libros de Arquitectura, edición prologada por D. Rodríguez, Madrid, Alianza, 2001, pp. 34 (Lib. I, cap. I) y 157 (Lib. VI, cap. VII)

31. FORSSMAN, E., Säule und ornament, Stockholm, Almquist and Wiksell, 1956, pp. 140 148, Die Karyatidherme oder Terme y pp. 148 156, Die abstrackte Terme. JULIEN, P., "Termes, atlantes et caryatides: corps et décors d'une architecture discursive, XVle XVIIle siècles", en Dekonick, R., Heering, C., Lefftz, M. (eds.), Questions d'ornements, XVe-XVIIIe siècles, Turn hout, Ed. Brepols, 2014, pp. 121135.

32. ARFE Y VILLAFAÑE, J., De Varia Commensuración para la esculputura y la architectura, Sevilla, 1585.

33. ALCIATO, A., Emblemas, edición y comentarios de S. Sebastián, Madrid, Akal, 1985, pp. 199200.

34. SEBASTIÁN LÓPEZ, S., "Los soportes antropomorfos y sus variaciones", Fragmentos, 89 (1986), p. 67. 
Cada uno de los hermes masculinos y femeninos presenta un diseño diferente y parecen corresponder a personas de distintas edades, mostrando ese rasgo manierista de las contraposiciones entre opuestos. Son estípites antropomorfos con basa y capitel jónico, mostrando cuatro de ellos el fuste acanalado y otros dos encadenados geométricos; en todos los casos son representados con el torso desnudo y sin brazos, acabando sus hombros en características espirales, como vemos en los que ilustran el frontispicio de las Constituciones Sinodales calagurritanas. Aunque Vitruvio asocia este orden con la mujer y sus volutas con los rizos de su peinado, en esta obra aparece también, de manera impropia, sobre los hermes masculinos, incidiendo en la degradación del hombre.

Los hermes de Lanciego guardan gran semejanza con los que vemos en estampas realizadas en la década de los cuarenta del siglo XVI por grabadores de la escuela de Fontainebleau y también con los que flanquean los frontispicios del tratado de Serlio y de las Sinodales de Calahorra y La Calzada de 1555. Este apoyo antropomorfo fue muy poco representado en la tratadística y los grabados italianos, con la notable excepción de la serie de Hermes (1536) de Agostino Veneziano, grabador rafaelesco. Fue en Francia donde este soporte gozó de gran éxito a partir de las decoraciones de estuco del Palacio de Fontainebleau, como las de los marcos que flanquean la escena de Cleobis y Biton; este motivo se multiplicó en grabados ornamentales de Boyvin, Fantuzzi o Mignon. Las dos últimas series con términos y cariátides fueron realizadas por Cornelis Bos (1546) y Jacques Androuet du Cerceau (1546-1549) ${ }^{35}$. Encontramos hermes de talla en el baldaquino del asiento episcopal de la sillería de coro de la catedral de Almería, realizada entre 1558 y 1561 por Juan de Orea, autor asimismo del facistol hoy desaparecido ${ }^{36}$. Resulta excepcional la sillería de coro que, procedente del monasterio de Santa María la Real de San Martín de Valdeiglesias, se conserva en la catedral de Murcia por los numerosos hermes que separan los tableros de la sillería baja. Fue realizada entre 1567 y 1571 por Rafael de León, entallador francés procedente de Lyon y avecindado en Toledo ${ }^{37}$. Conviene recordar por último que en el frontispicio de la obra Orlando el Furioso de Ludovico Ariosto, impresa por Matías

35. A la serie de Du Cerceau siguieron otras como las de H. Vredeman de Vries (1565), H. Sambin (1572), y W. Dietterlin (1593 1594). THOMAS, E., "Termes et caryatides dans les des sins et gravures de Jacques Androuet Du Cerceau", en Dekonick, R., Heering, C., Lefftz, M. (eds.), Questions d,ornements, XVe-XVIIle siècles, Turnhout, Ed. Brepols, 2014, pp. 136143.

36. NICOLÁS MARTÍNEZ, M. M., y TORRES FERNÁNDEZ, M. R., "Arte y fisiognomía en la galería de cabezas del coro de la catedral de Almería", Congreso Internacional Imagen Apariencia, Murcia, Universidad de Murcia, 2009, s. p.

37. CRUZ ARIAS, M. J. y FRANCO MATA, A., "Nuevos documentos sobre el escultor y enta llador Rafael de León", Anales Toledanos, 17 (1983), pp. 87115. 
Marés en Bilbao en 1583, aparecen dos hermes, masculino y femenino, al igual que en la edición veneciana de $1556^{38}$.

Esta pieza excepcional que es el facistol de Lanciego alberga el conjunto de hermes más notable de todo el País Vasco y La Rioja que pudo salir de la gubia de Arnao de Bruselas o de alguno de sus seguidores. En Álava solo pueden compararse con los que flanquean la calle central del retablo pétreo de la capilla de San Francisco de Salvatierra o con la pareja que enmarca la portada de la sacristía de Alegría, ambas realizadas en torno a 1574. Sin este carácter tectónico los hermes decoran zonas de talla de retablos manieristas como los de Elvillar o Urbina. Para encontrar otro conjunto significativo de hermes tenemos que desplazarnos hasta la vecina localidad navarra de Torralba del Río (1574-1580), donde encontramos el mayor número y variedad de este soporte en las barandillas de su coro y en el sotocoro ${ }^{39}$. Es precisamente en el Viejo Reino donde se han localizado verdaderos especialistas en estípites y cariátides manieristas, en la década de los setenta del siglo XVI, como los entalladores Juan de Elordi y Pierres Picart y el imaginero Miguel de Espinal, autores de retablos de transición al Romanismo ${ }^{40}$. La parroquia navarra de Ochagavía muestra en su retablo mayor y los frentes de la sillería de coro, contratados en 1574 por Espinal, un buen número de hermes como pervivencia de un lenguaje fantástico que pronto va a quedar en desuso. Así lo manifiesta la reacción de patronos y vecinos cuando se quejan de que había realizado "veynte y seys figuras deshonestas, que son monstruos medio hombres y medio bestias y los Ilaman termas" ${ }^{41}$.

Las seis figuras antropomorfas del pilar de Lanciego se pueden agrupar por parejas que caracterizan tres edades del hombre, la juventud, la madurez y la vejez. La herma femenina con rostro y cuerpo juveniles lleva como adornos una diadema y un collar con colgante, marcando la transición al estípite una cartela correiforme con tela colgante y ensarto de frutos. A la derecha aparece un joven de barba larga y curvilínea que muestra en su cintura otra cartela doblada con flores y telas colgantes, idénticas a las que vemos en un grabado con marina de J. Mignon (fig. 5); como hemos señalado, repite en sus rasgos los de uno de los soldados de la escena de San Martín partiendo la capa de la sillería de La Redonda de Logroño. Les sigue una mujer madura de formas más rotundas y

38. RODRÍGUEZ PELAZ, C., "La ilustración en los libros de Mathías Marés, primer impresor de Bizkaia", Kobie, 11 (1995 1997), pp. 171172.

39. GARCIA GAINZA, M. C. (dir.) y otros, Catálogo Monumental de Navarra, T. II**, Pam plona, Institución Príncipe de Viana, 1983, pp. 520521.

40. ECHEVERRÍA GOÑI, P. L., "El retablo mayor de Lerate y la transición entre los dos rena cimientos en el taller de Villanueva de Araquil" en Cátedra de Patrimonio y Arte Navarro. Memoria, Pamplona, Gobierno de Navarra, 2011, pp. 291292.

41. GARCíA GAINZA, M. C., "Miguel de Espinal y los retablos de Ochagavía", Príncipe de Viana, 108109 (1967), pp. 345346. 

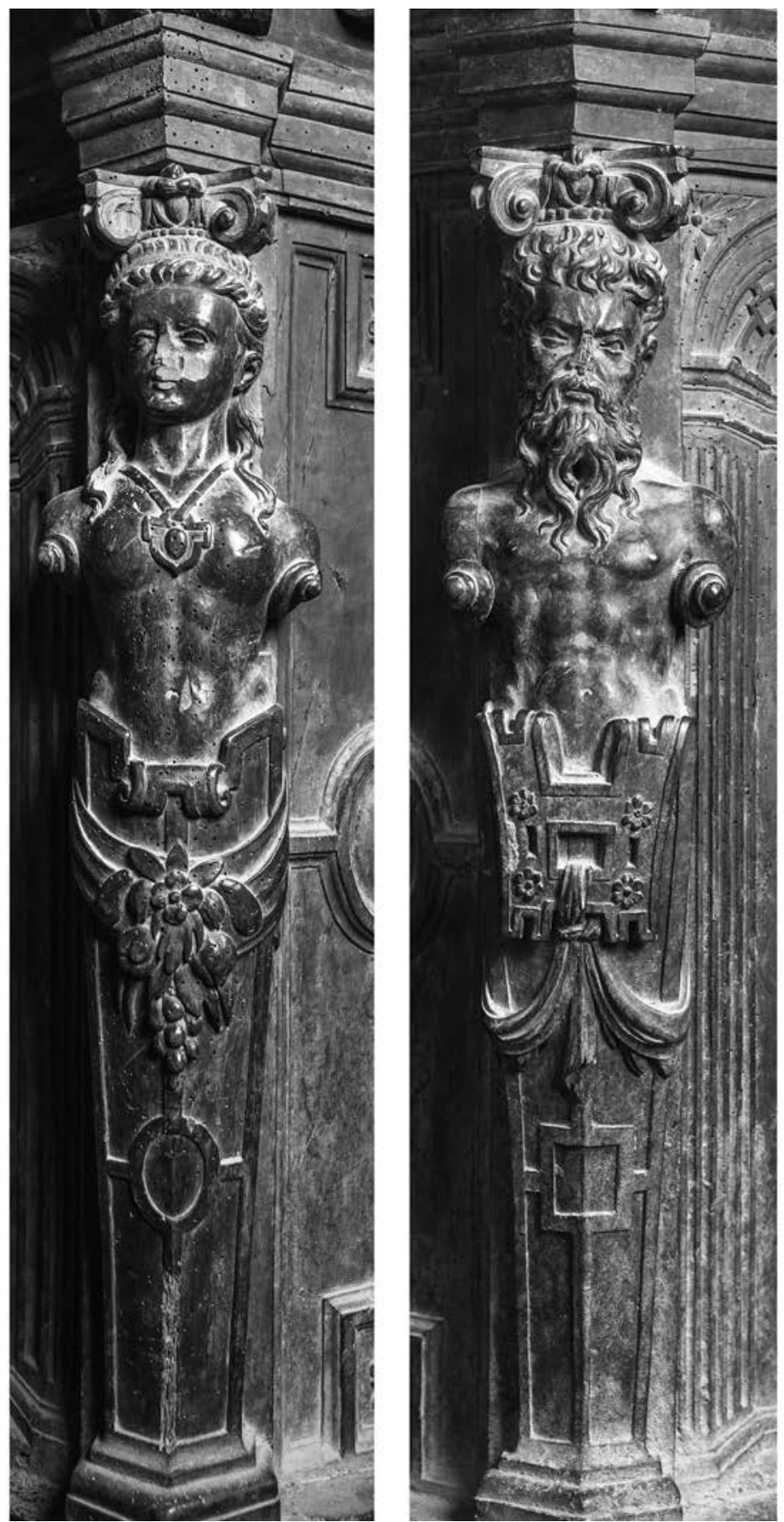

Figura 5. Hermes femenino y masculino. 


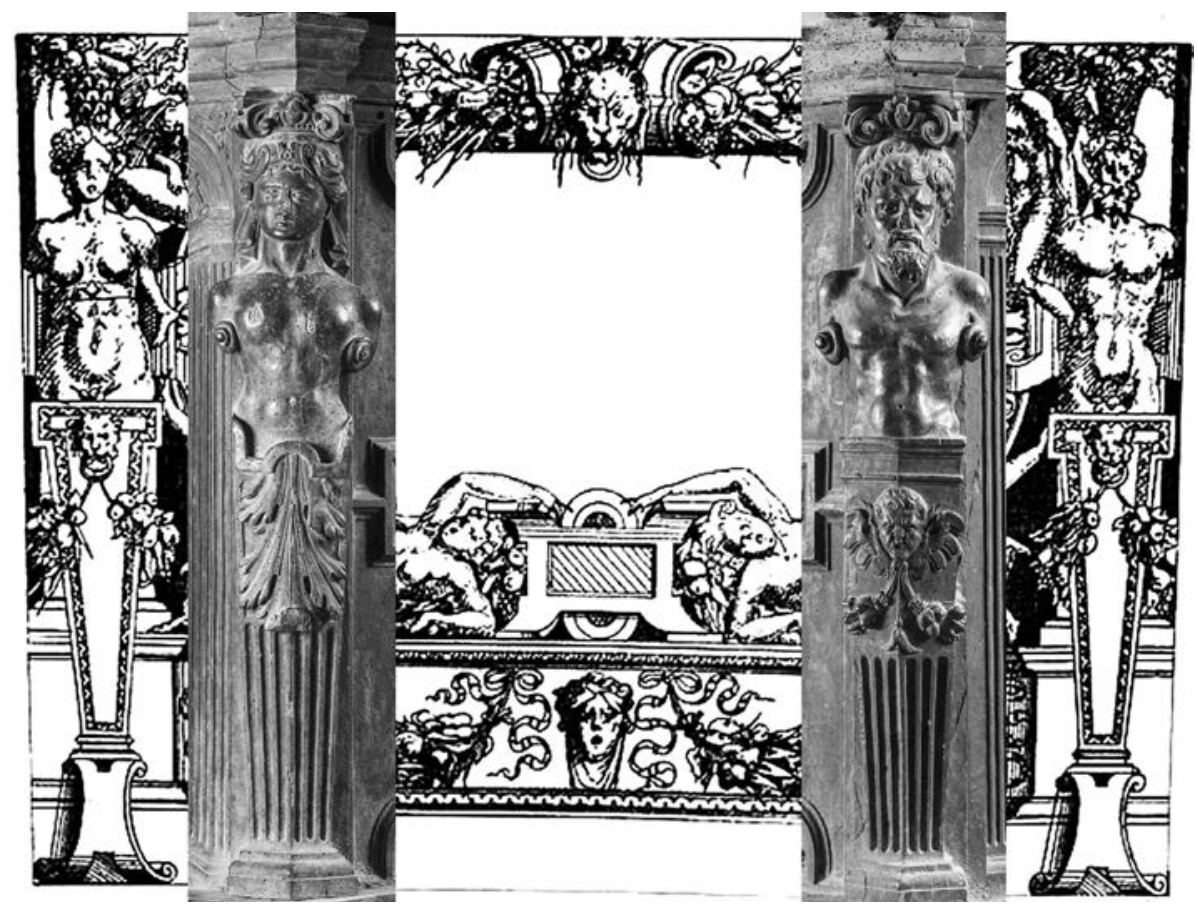

Figura 6. Cartela ornamental de J. A. du Cerceau. Hermes femenino y masculino del facistol.

rostro de matrona prerromanista, que cubre su cabeza con un tocado con diadema correiforme del que cuelga el velo; entre el torso y la pirámide invertida vemos una decoración foliácea. Su pareja es un hombre de barba corta, ostentando como elemento de transición una cabeza alada grotesca de la que penden sendas guirnaldas de frutos. Estos hermes nos recuerdan a los que encuadran una cartela diseñada por Du Cerceau ${ }^{42}$ (fig. 6). La vejez se representa aquí mediante una anciana de rostro arrugado y embozado, en parte perdido, resultando expresivos en esta caracterización los pechos caídos; cubre su tercio inferior con una falda larga. En algunos hermes femeninos, realizados por grabadores franceses, vemos repetido el rasgo de los pechos flácidos como por ejemplo el de H. Sambin de mujer anciana con putti en su base, realizado en $1554^{43}$. Su compañero es un viejo de barba corta y turbante que muestra en su parte inferior otra cartela de cueros y mascarón con cuernos de los que pende

42. Oeuvre de Jacques Androuet dit du Cerceau, Meubles, París, 1886, lám. 63.

43. Metropolitan Museum. New York. Prints, Ornament and Architecture. Number: 1983. 1137. 

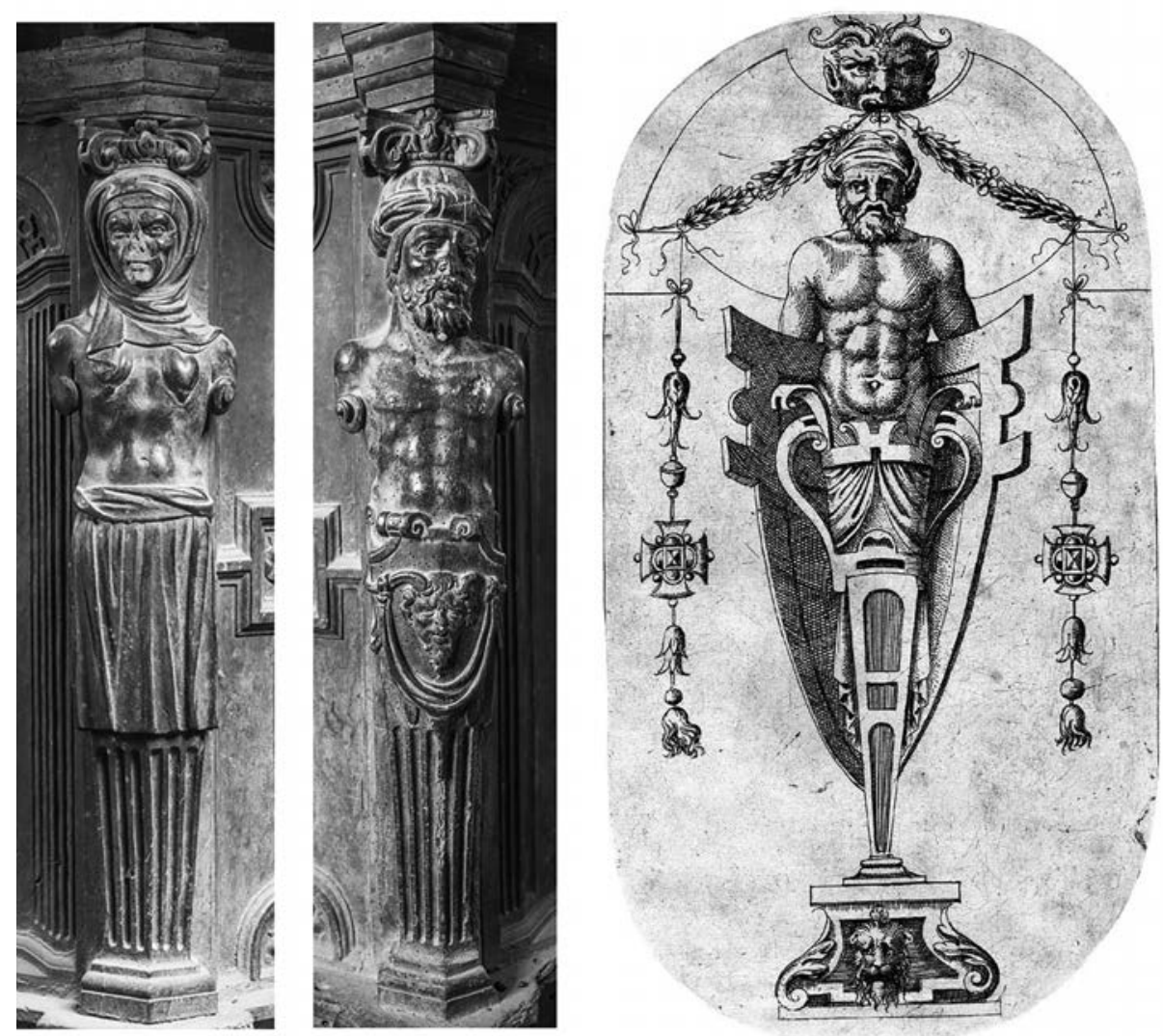

Figura 7. Hermes femenino y masculino del facistol. Hermes con máscara de sátiro, grabado de J. Mignon.

una tela. Guarda gran semejanza con el grabado de J. Mignon de un hermes con rostro de anciano barbado y turbante, inserto en una cartela correiforme, sobre cuya cabeza se dispone otra máscara de sátiro (1543-1545) (fig. 7).

La peana que sirve de asiento al atril adopta forma de pirámide hexagonal truncada, en cuyos vértices aparecen potentes ménsulas foliáceas de doble voluta decoradas con flores; encontramos ménsulas similares en la sillería de coro de La Redonda de Logroño, realizada en 1555 por Juan de Lorena. En sus seis paneles trapezoidales se representan, en marcos correiformes, dos ángeles y cuatro máscaras. Las dos masculinas llevan respectivamente cuernos y una luna sobre la frente, en tanto que las femeninas se cubren con turbante y diade-

44. British Museum. Department of Prints and Drawings. Museum Number: 1850,0527.230. 

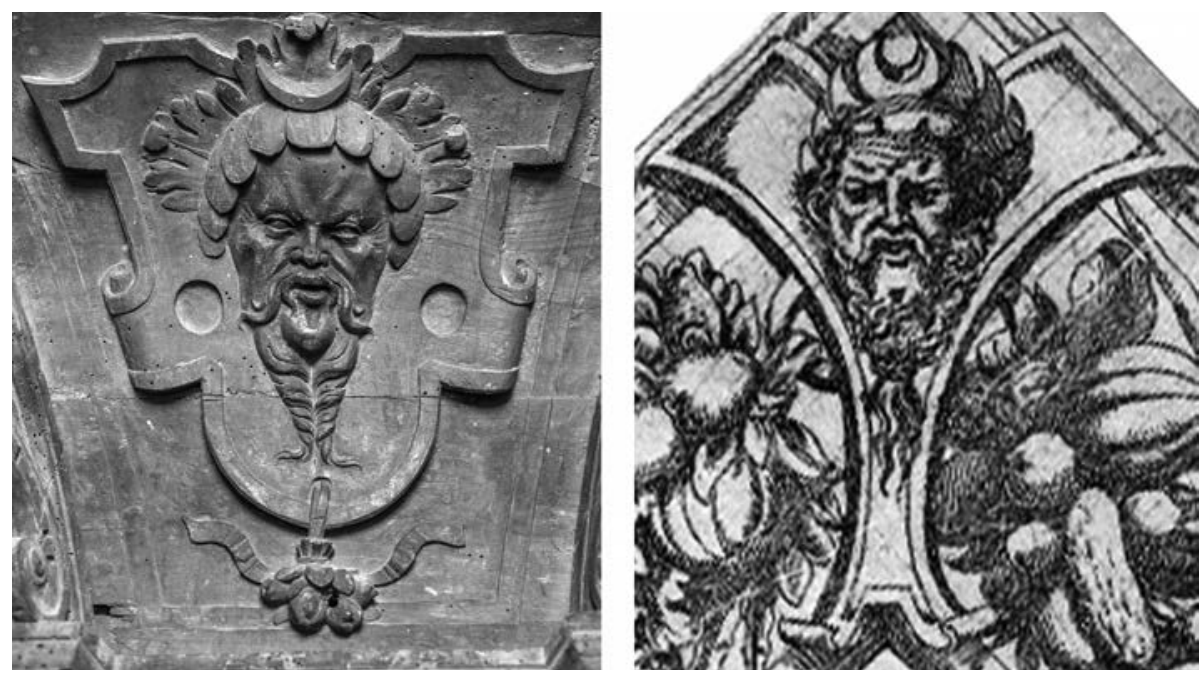

Figura 8. Máscara grotesca con luna en la peana. Máscara, detalle de un grabado de A. Fantuzzi.

ma. Estas máscaras manieristas son ornamentos de origen clásico que debemos poner en relación con las utilizadas en el teatro y, por su carácter superpuesto, son símbolo del engaño; encontramos máscaras humanas de adorno y otras grotescas con hibridaciones y deformaciones. Estos motivos se repiten en diferentes cartuchos ornamentales de Fontainebleau de los que los artistas los entresacaron e intercambiaron para adaptarlos a nuevos marcos.

La máscara grotesca con cuernos es la imagen de un sátiro con expresión airada, orejas puntiagudas y rostro peludo, trasladando a la talla los rasgos de las que aparecen en grabadores como Fantuzzi ${ }^{45}$, Boyvin o Mignon. La que luce una luna sobre su cabeza muestra expresión huraña, diadema llameante y barba trenzada, elementos que vemos repetidos en un grabado de 1540-1545 de Fantuzzi, en concreto en el marco de una cartela con matrona clásica ${ }^{46}$ (fig. 8). La luna aparece repetida más frecuentemente en máscaras femeninas de los mismos grabados belifontianos. El turbante, la toca y el velo y la diadema de cuero de la máscara femenina los encontramos en grabados franceses y flamencos como los de Fantuzzi y Bos (fig. 9). La mujer del turbante con nudos es parecida a la máscara que vemos en el grabado de J. Mignon de la Muerte de Adonis (1543-1545) ${ }^{47}$ (fig. 10). Los úni-

45. Ibid., Museum Number: 1850,0527.141. Se encuentra en el marco de una cartela con escena de puerto realizada entre 1542 y 1543.

46. Ibid., Museum Number: 1851,0208.152. Este grabado parece estar basado en una com posición de Giulio Romano para el palacio del Té de Mantua.

47. Ibid., Museum Number: 1850,0527.141. 
cos ornamentos que aparecen en la parte conservada de la sillería de coro de la parroquia de San Juan de Laguardia, son dos mascarones fantásticos localizados en la parte inferior de uno de los tableros y en la única misericordia decorada. Ente los motivos pintados en 1561 en la bóveda del coro de la parroquia de San Antolín de Urbina por Juan de Elejalde, encontramos un amplio repertorio de máscaras y mascarones como los de este facistol riojano ${ }^{48}$.

Los últimos motivos manieristas que aparecen en este facistol son las cartelas de cueros recortados ${ }^{49}$ que, como señaló E. Forsmann, son el único motivo del manierismo fantástico que no tiene antecedentes en el arte clásico, debiéndose su creación a Miguel Ángel, para diseños de carpintería. Son un elemento de encuadramiento imprescindible en grabados ornamentales de la escuela de Fontainebleau como los de Du Cerceau. Situadas en la peana y el pie del facistol, adoptan formas trapezoidales y siluetas mixtilíneas y acogen cabezas de ángeles y máscaras. Su superficie se adorna con flores y perforaciones circulares.

Este excepcional facistol de Lanciego solo admite comparación con otros dos muebles coetáneos de la

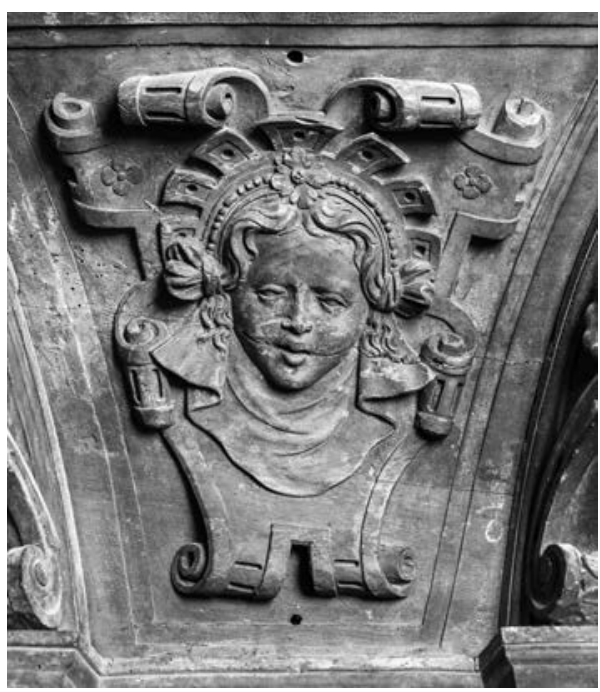

Figura 9. Máscara femenina con diadema de cueros.

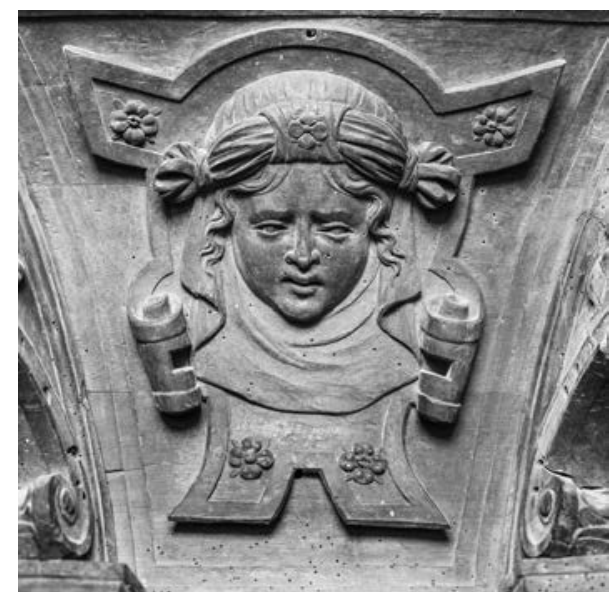

Figura 10. Máscara femenina con turbante.

48. ECHEVERRÍA GOÑI, P. L. y VÉLEZ CHAURRI, J. J., "El retablo mayor y la pinceladura de la parroquia de San Antolín de Urbina. Un conjunto singular del Renacimiento alavés", en POR TILLA VITORIA, M. J., Catálogo Monumental. Diócesis de Vitoria, T. IX, El valle de Zuia y las tierras de Legutiano, Vitoria, Fundación Caja de Ahorros de Vitoria y Álava, 2007, pp. 260263.

49. FORSSMAN, E., ob. cit., pp. 112 119. Das Rollwerk. SPEELBERG, F., "Ordine con piu ornament. Reconsidering the origins of strapwork ornament in relation to the emancipation of the ornamental frame", en Dekonick, R., Heering, C., Lefftz, M. (eds.), Questions d,ornements, 
zona, como son el facistol de la parroquia de Santa María de Los Arcos (Navarra), realizado a partir de 1561 y el púlpito del monasterio de San Millán de la Cogolla (La Rioja) ejecutado en torno a 1555 y atribuido a Juan de Lizarazu ${ }^{50}$. El primero, obra como vimos de Martín Gumet y Juan Ruiz de Heredia, presenta un completo repertorio del manierismo fantástico en base a cartelas correiformes, atlantes, hermes masculinos y femeninos y angelitos ${ }^{51}$. En la sillería de la que forma parte se añaden a estos motivos telas colgantes, mascarones, encadenados geométricos y pilastras con arcos en perspectiva. El pulpito riojano, que también se había puesto en relación con el estilo de Andrés de Araoz ${ }^{52}$, guarnece los ángulos de su antepecho con hermes masculinos y femeninos dispuestos sobre telamones y ménsulas y, al igual que en Lanciego, muestra asimismo cartelas correiformes y encadenados geométricos.

XVe-XVIIle siècles, Turnhout, Ed. Brepols, 2014, pp. 159163 (sobre las cartelas correiformes en Fontainebleau)

50. Atribuido al imaginero guipuzcoano Juan de Lizarazu (Juan de Villarreal) afincado en Burgos por BARRÓN GARCíA, A., "Proceso constructivo del claustro de San Millán de la Cogo Ila por Juan Pérez de Solarte", Brocar, 38 (2014), pp. 142142.

51. GARCÍA GAINZA, M. C. (dir.) y otros, Catálogo Monumental de Navarra, T. II*, Pamplo na, Institución Príncipe de Viana, 1982, pp. 215217.

52. WEISE, G., Die Plastick der Renaissance und des Frübarock in nordlinchen Spanien, Tubinga, 1957 1959, 2 vols. RAMíREZ MARTíNEZ, J. M., "El Monasterio de San Millán de Yuso", El Chapitel, nº 6 (1998), p. 43. 